\title{
Проблемы юридического и лингвистического определения фальсификации доказательств в уголовном судопроизводстве
}

\author{
А.Ю. Сафронов ${ }^{1}$, В.В. Поляков ${ }^{2}$ \\ ${ }^{1}$ Российский государственный университет правосудия \\ 658481, Алтайский край, г. Змеиногорск, ул. Ленина, 41. \\ E-mail:safronov.au@gmail.com \\ ${ }^{2}$ Алтайский государственный университет \\ 656049, Алтайский край, г. Барнаул, пр. Сочиалистический, 68. \\ E-mail:agupolyakov@gmail.com
}

\begin{abstract}
В статье осуществляется многоаспектный анализ юридических понятий «фальсификация доказательств по уголовному делу", "фальсификация результатов оперативно-розыскной деятельности» и «фальсификация электронных доказательств по уголовному делу», даются их авторские определения. Обосновывается, что правовая оценка письменной речевой деятельности зависит от юридической стороны вопроса, и наоборот - квалификация деяния как преступной фальсификации неизбежно определяется толкованием юридических терминов. Рассматривается история юридического понятия «фальсификация», его происхождение и эволюция.

Отмечается, что с развитием информационных технологий значительную актуальность приобрели юридические и лингвистические вопросы «фальсификации электронных доказательств». Любое доказательство может иметь как бумажный, так и электронный вид, либо один вид доказательства может быть продублирован другим, поэтому при описании способов и признаков фальсификации (подделки) документов необходимо разграничивать их печатную (материальную) и электронно-цифровую разновидности. При обнаружении фальсификации электронных документов необходима в обязательном порядке фиксация фальсификации данных на бумажном носителе в соответствующих материалах уголовного дела. Учитывая совокупность криминалистического, уголовно-правового и уголовнопроцессуального аспектов, фальсификация электронных доказательств становится преступной только тогда, когда она находит свое очевидное отражение в материалах уголовного дела, то есть в акте правоприменения уполном оченного лица, зафиксированном на бумажном носителе. Утверждается, что в силу ряда причин сложилась благоприятная ситуация для активного использования фальсификации электронных доказательств в высокотехнологичных преступлениях.
\end{abstract}

Ключевые слова: фальсификация; доказательства; электронный документ электронное доказательство; высокотехнологичные преступления

\section{Problems of legal and linguistic definition of evidence tampering in criminal court procedure}

\author{
A.Yu. Safronov ${ }^{1}$, V.V. Polyakov ${ }^{2}$ \\ ${ }^{1}$ Russian State University of Justice \\ 658481, Altai Krai,Zmeinogorsk, ul.Lenina,41.E-mail:safronov.au@gmail.com \\ ${ }^{2}$ Altai State University \\ 656049, Altai Krai, Barnaul, Socialist Ave., 68. E-mail: agupolyakov@gmail.com
}

The article provides multi-faceted analysis and gives new definition to the legal concepts "tampering with evidence on a criminal case", "tampering with the results of investigative work", "tampering with electronic evidence on a criminal case". The article 
discusses that legal assessment of written speech depends on legal bearings of the case, while labeling process as an evidence tampering depends on interpretation of legal norms. The history of the term "evidence tampering" is given as well as its origin and evolution.

It's noted that IT development has brought attention to legal and linguistic aspects of "electronic evidence tampering". Any evidence can be either in paper or electronic form, or one piece of evidence can be backed up by the other, that's why it is important to differentiate printed (material) and digital types when describing ways and features of evidence tampering (forger). When edocument tampering is found, it is always necessary to record the fact of it on paper in the corresponding criminal case file. In accordance with the complex of criminalistics, criminal law and procedure aspects, electronic evidence tampering becomes felonious only if it is recorded in a criminal case file which is an administration of law by an authorized officer and which is written on paper. It is claimed that for a variety of reasons there has been a favorable situation for active use of electronic evidence tampering in hi-tech crimes.

Keywords: tampering; evidence; electronic document; electronic evidence; hi -tech crimes

Проблема фальсификации доказательств возникла давно и продолжает оставаться актуальной до настоящего времени. Несмотря на важность этой проблемы, ее комплексное научное исследование не проводилось. В литературе встречаются работы, посвященные отдельным аспектам этого вопроса уголовно-правового, уголовно-процессуального криминалистического и лингвистического характера.

Термин «фа льсификация» - от латинского «falsifico» - имеет следующие значения: преднамеренное иска жение чего-либо; изменение (подделка) с корыстной целью вида или свойств объе ктов. В историческом пла не о процессуальной проблеме фальсификации речь начала идти уже в середине 16 столетия. Так, Судебник Ивана Грозного устанавливал ответственность за составление подложных протоколов суде бного разбирательства, подделку речей истца или ответчика. В последующем, начиная приме рно с 18 столетия, понятие фа льсификации было распростране но и на документы, подвергшиеся редактированию по политическим и идеологическим мотивам.

На сегодняшний день остаются важные вопросы, отсутствие правовой определённости по которым вызывает ряд проблем юридического толка. Речь идет о понятиях: «фальсификация доказательств по уголовному делу» и «фальсификация результатов оперативно-розыскной деятельности». Для определения данных понятий необходимо проанализировать базовые законодательные и научные положения в этой области. Так, важной в понятийном аппарате криминалистики работе профессора Р. С.Белкина «Криминалистика: учебный словарь-справочник» [Белкин 1999: 268] уделяется внимание фальсификации следов рук и фальшивомонетничеству. В «Энциклопедии судебных экспертиз» дается следующее определение: фальсификация (подделка) изготовление поддельных объектов, имитирующих подлинные, подмена подлинного (настоящего) ложным (мнимым) [Аверьянова, Россинская 1999: 551]. В Уголовном кодексе (далее -УК) РФ имеется 6 статей, прямо посвященных фа льсифика ции, а именно, это статьи: 142, 142.1, 170.1, 172.1, 185.5 и ст. 303 УК РФ - Фальсификация доказательств и результатов оперативно-разыскной деятельности.

Можно сделать вывод, что в статьях УК РФ в своем ракурсе раскрывается часть ключевого понятия - «фальсификация». К примеру, в ст.142 УК РФ под фа льсифика цией понима ется созна тельное внесение ложных сведений в документы, чтобы добиться нужных для определенных лиц результатов выборов или проведения референдума, а под ложными сведениями - действия по искажению документа, замене подлинного документа другим и т. д. В соответствии со ст. 303 УК РФ под «фа льсификацией» понима ется иска жение фа ктиче ских данных, являющихся доказательствами и (или) результа тами опе ративно -розыскной деятельности. Она может проявляться в разных формах: внесение дополнительного текста в документы, их подделка, подчистка, пометка другим числом. Кроме того, выделяют интеллектуа льный подлог, который подразумевает представление ложных доказательств по содержанию.

Таким образом, говоря об определении рассматриваемых юридических понятий, мы неизбежно обращаемся к УК РФ и Федеральному закону "Об оперативно-розыскной деятельности». Юридическая квалификация деяния в качестве преступной фальсификации неизбежно определяется толкованием юридических терминов «фальсифицируемые доказательства» и (или) «результаты оперативно-розыскной деятельности». При определении ра ссматриваемого понятия как преступного требуется проведение качественной предварительной проверки заявления (сообщения) о преступной фальсификации [Са фронов 2015: 142-144].

Согласно ч. 2 ст. 74 Уголовно-процессуальному кодексу РФ, фальсификация доказательств выраже на в подделке (искажении) показаний подозреваемого, обвиняемого, потерпевшего, свидетеля; заключения и (или) показаний эксперта или специалиста; вещественного доказательства, протоколов следственных и судебных действий, а также иных документов. К последним, при соблюдении определённой законом (в том числе - Уголовно-процессуальным) процедуры, можно отнести и результаты оперативно-розыскной деятельности, на пример: контроль почтовых отправлений, телеграфных и иных сообщений; прослушивание телефонных переговоров; снятие информациис технических каналов связи; получение компьютерной информации.

Определяя понятия «фальсификации доказательств по уголовному делу» и «фальсификации результатов оперативнорозыскной деятельности», нельзя вновь не обратиться к обозначенным выше Федеральным законам, в части определения круга субъектов совершения рассматриваемых преступлений (лицо, производящее дознание, следователь, прокурор илиза щитник, а та кже лицо, уполномоченное на проведение оперативно-разыскных мероприятий). Указание на данныхсубъектов при определениипонятий необходимо, так как только имиможет быть совершена фальсификация.

Таким образом, под термином «фальсификация доказательств по уголовном делу» нужно понимать подделку (искажение) показаний подозреваемого, обвиняемого, потерпевшего, свидетеля; заключений и (или) показаний эксперта или специалиста; вещественных доказательств, протоколов следственных и судебных действий, либо иных документов, осуществлённую лицом, производящим дозна ние, следователем, прокурором или за щитником.

При определении понятия «фальсификация результатов оперативно-розыскной деятельности» Уголовный закон также содержит императивное указание на необходимость установления целей деяния: «... уголовное преследование лица, заведомо непричастного к совершению преступления, либо ... причинение вреда чести, достоинству и деловой репутации». Подытоживая сказанное, сформулируем понятие «фальсификация результатов оперативно-розыскной деятельности» как подделку (искажение) результатов оперативно-розыскных мероприятий, совершенную лицом, уполномоченным на их проведение, в целях уголовного преследования лица, заведомо непричастного к совершению преступления, либо совершаемое в целях причинения вреда чести, достоинствуи деловой репутации.

На сеголняшний день с развитием информащионных технологий значительную актуа пьность приобрели юриидические ц 
лингвистические вопросы фальсификации принципиально нового вида доказательств - электронных данных. Нужно признать, что полноценное использование электронных доказательств в суде в настоящее время затруднено из-за неразработанности нормативной базы и недостатка адекватных кримина листических методик их получения, отвечающих требованиям допустимости, относимости и достоверности [Васюков 2016: 54-57]. В результате сложившиеся противоречия и неопределенности, отсутствие единообразия правоприменения, различное толкование ключевых понятий и терминов ведут к тому, что имеются серьезные проблемы по сбору, исследованию, оценке и использованию электронных данных в доказывании. На наш взгляд, к многочисленным проблемам использования в уголовном судопроизводстве электронных доказательств добавляется недостаточность технической компетентности судей, прокурорских работников, адвокатов и потерпевших, которые самостоятельно (без специальных познаний) не могут выявить фальсификацию электронных доказательств, что создает благоприятную почву для откровенной фальсификации электронных доказательств [Поляков 2010: 96-97]. При этом выявление и доказывание таких фактов, в том числе по названным причинам, является еще более маловероятным и малоперспективным (см., на пример, приговор Московского городского суда от02 июля 2018 г. по делу N 2 0020/2018). Анализ криминалистической литературы, судебно-следственной практики и анкетирования сотрудников пра воохранительных органов, экспе ртов и специа листов по информа ционным технологиям и информа ционной безопа сности позволил опреде лить крайне высокую степень латентности фальсификации электронных доказательств, отчего данную ситуа цию необход имо оценить как опасную и требующую научно-практического разрешения [Поляков 2008: 245 - 249]. Полагаем, что это порождает рост высокотехнологичных преступлений, в которых важнейшая роль отводится сокрытию преступлений и противодействию следствию. [Поляков 2012: 11-12].

С методологической и практической точек зрения для уголовного судопроизводства важно сначала определиться с содержанием иобъемом понятия "электронные доказательства», толкуемого как электронно -цифровые следы преступления (Поляков 2013), а потом проана лизировать возможности их фальсификации. Вслед за А.М. Ба рановым будем исходить из того, что при аналиве использования доказательств, полученных с помощью средств компьютерной техники «необходимо, чтобы форма не мешала технологии процесса, а устанавливала общие правила производства и сбора доказательств, обеспечивала пра во лиц на определенном этапе производства». [Баранов 2006: 146-147]. В настоящее время наиболее адекватным развитию криминалистической теории и судебно-следственной практики для характеристики формы является специфическое понятие «электронный документ». Согласно законодательству, "документированная информация - зафиксированная на материальном носителе путем документирования информация с реквизитами, позволяющими определить такую информацию или в установленных законодательством Российской Федерации случаях ее материальный носитель» (Федеральный закон "Об информации, информационных технологиях и о защите информации" от 27.07.2006 № 149-Ф3). Понятие “электронный документ» в силу неразработанности теории, относящейся к использованию электронных доказательств, вызывает большие дискуссии в криминалистике [Поляков 2008: 427-431]. П. П. 3айцев справедливо акцентирует внимание на том, что в процессуальном праве, в нормативно -правовых актах и руководящих разъяснениях судам для обозначения формы представления компьютерной информации «используются различные термины: «электронный документ», «документ, подготовленный с помощью электронно-вычислительной техники», «ма шинный документ» [3айцев 2002: 40-44]. Под электронным документом В. Б. Вехов понима ет «сведения о лицах, предметах, фа ктах, событиях, явленияхи процессах в электронноцифровой форме, за фиксирова нных на машинном носителе с помощью электромагнитных сигналов с реквизитами, позволяющими идентифицировать данные сведения» [Вехов 2005: 11-13]. Также В.Б. Вехов предлагает использовать такое понятие как «комбинирова нный документ», который содержат «одновременно машинописные, рукописные иэлектронные реквизиты», на пример, им может выступа ть SIM-карта [Вехов 2008: 96]. Интересной представляется точка зрения В. А. Мещерякова [Мещеряков 2004: 153-169], который предлагает расширить понятие «электронный документ» и за менить его на понятие «электронный цифровой объект», однако сам автор выражает сомнение в готовности за конодателя принять его предложение.

Учитыва я специфику современного уголовного судопроизводства, любое доказательство может иметь как бумажный, так и электронный вид, либо один вид доказательства может быть продублирован другим. К примеру, электронные документы, в которых содержатся лог-фалы об истории посещения сайтов, сетевых соединениях, подключенных на копителях данных или иных сведений о преступлении, находят свое отражение в протоколах следственных действий, например, осмотра, выемки, экспертизы. Полагаем, что при фальсификации электронных документов в обязательном порядке будет присутствовать фальсификация данных на бумажном носителе в материалах уголовного дела (Апелляционное определение судебной коллегии по уголовным делам Суда Ханты-Мансийского а втономного округа от 12 апреля 2018 г. по делу N 22-411/2018). Вместе с тем, учитыва я совокупность кримина листического, уголовнопра вового и уголовно-процессуального аспектов, фальсификация эле ктронных доказательств может стать преступной только тогда, когда она находит свое очевидное отражение в материалах уголовного дела, то есть в актах правоприменения уполномоченных лиц, за фиксирова нных на бума жных носителях. В противном случае, фа льсифика ция электронных данных не будет воспринята судом, либо прокурором и, соответственно, не будет иметьдоказательственного значения, что делает ее осуществ ление бессмысленным, так как она не создаёт угрозы привлечения к уголовной ответственности.

Определяя понятие «фальсификация электронных доказательств по уголовному делу», приходимк выводу, что это подделка (искажение) показаний подозреваемого, обвиняемого, потерпевшего, свидетеля, за ключений и (или) показа ний эксперта или специалиста, вещественных доказательств, протоколовследственных и судебных действий, либо иных документов, осуществленна я лицом, производящим дознание, следователем, прокурором или защитником, нашедшая отражение в электронном и бумажном носителе по уголовномуделу.

Резюмируя вышесказанное, делаем вывод о том, что во вза имосвязи кримина листического, уголовно -правового, уголовнопроцессуа льного и лингвистического аспектов лежит ключ к пониманию понятий рассматриваемых разновидностей фальсификации. Компле ксный а на лиз да нных аспектов позволил сформулировать не обходимые для уголовного судопроизводства понятия, связа нные с фальсификациейдоказательств.

\section{Литература}

1. Апелляционное Определение Судебной коллегии Лангепасского городского суда Ханты-Мансийского автономного округа от 12 апре ля 2018 г. по делу N 22-411/2018 / Архив Лангепа сского городского суда Ханты-Мансийского а втономного округа, 2018 г.

2. Приговор Московского городского суда по делу N 2-0020/2018 от 02 июля 2018 г.). Апелляционное определение Судебной коллегии по уголовным делам Верховного Суда РФ от 7 ноября 2018 г. N 5-АПУ18-67 / Архив Московского городского суда г. Москвы, 2018 г. 
3. Аверьянова Т. В., Россинская Е. В. Энциклопедия судебной экспертизы. М. 1999.

4. Баранов А. М. Обеспечение законности в досудебном производстве по уголовным делам / А. М. Баранов. - Омск: Омская академия МВД Росии. 2006. - С. 146-147.

5. Белкин Р. С. Кримина листика: учебный словарь-справочник. М. 1999.

6. Васюков В.Ф. Изъятие электронных носителей информации: нерешенные проблемы практики / В. Ф. Васюков / Уголовный процесс. - 2016. - №2. - 54-57.

7. ВеховВ.Б. Основные направления развития криминалистического исследования компьютерной информации и ее материальных носителей / В. Б. Вехов / Раскрытие и расследование преступлений, сопряженных с использованием средств вычислительной техники: проблемы, тенденции, перспективы: материалы Все российской научно-практической конференции - М. 2005. - C. 11-13.

8. Вехов В.Б. Основы кримина листического учения об исследовании и использовании компьютерной информа ции и средств ее обработки / В. Б. Вехов. - Волгоград: 2008. - С. 96.

9. Зайцев П. Электронный документ какисточник доказательств / П. Зайцев / Законность. - 2002. - № 4. - С. 40 - 44.

10. Мещеряков В.А. Электронные цифровые объекты в уголовном процессе и криминалистике / В. А. Мещеряков / Воронежские кримина листические чтения: сборных научных трудов / под редакцией О. Я. Ба ева. - Воронеж: 2004. - Выпуск 5. - С. 153 - 169.

11. Поляков В.В.К вопросу о повышении эффективности расследования преступлений в сфере компьютерной информации / В. В. Поляков / Актуальные проблемы борьбы с преступлениями и иными правонарушениями: материалы Четвертой Междуна родной научно-пра ктической конференции. - Барнаул: 2006. - С. 93-94.

12. Поляков В.В.К вопросу об использова нии понятий «виртуа льные следы» и «электронно-цифровые следы» в кримина листике / В. В. Поляков, А. В. Шебалин / Актуа льные проблемы борьбы с преступлениями и иными правонарушениями: материалы одиннадцатой Междуна родной научно-практической конфе ренции. В 2-х ча стях. - Барнаул: Барнаульский юридический институт МВД России, 2013. Ча сть 1. - С. 123-125.

13. Поляков В.В. О высокотехнологичных способах сове ршения преступлений в сфере компьютерной информа ции / В. В. Поляков / Уголовно-процессуальные и криминалистические чтения на Алтае: материалы ежегодной Всероссийской научно-практической конфе ренции, посвященной 50-летию юридического фа культета и 40-летию Алтайского государственного университета. - Ба рнаул: Издво АлтГУ. 2012. Выпуск 11-12. - С.123 - 126.

14. Поляков В.В. Об использовании новых понятий при доказывании преступлений в сфере компьютерной информации / В.В. Поляков / Российская юридическая наука: состояние, проблемы, перспективы: материалы Всероссийской на учно-практической конференции, посвященной 45-летию юридического образования на Алтае, 19-20 сентября 2008. - Ба рнаул. 2008. - С. 427 - 431.

15. Поляков В.В. Особенности подготовки специалистов для расследования преступлений, связанных с неправомерным уда ленным доступом к компьютерной информа ции / В. В. Поляков/ Известия Алтайского государственного университета. 2010. - N 2/1. - С. 96 - 97.

16. Поляков В.В. Результаты анкетирования по делам о неправомерном удаленном доступе к компьютерной информации / В.В. Поляков // Уголовно-процессуальные и кримина листические чтения на Алтае: материалы межрегиональной научно-практической конференции / под редакцией В. К. Га вло. - Ба рнаул: Изда тельство Алтайского государственного униве рситета. 2008. - Выпуск 7. - С. 245 $-249$.

17. Сафронов А.Ю. О необходимости разграничения фальсификации и добросовестного заблуждения в ходе производства проверок по заявлениям (сообщениям) о фальсификации доказательств и фальсификации результатов оперативно-розыскной деятельности. Томск. 2015. С. 142-144.

18. Сафронов А. Ю. Способы совершения преступления по уголовным делам о фальсификации доказательств и (или) результатов оперативно-розыскнойдеятельности. Барнаул. 2017. С. 122-127.

19. Са фронов А. Ю. Структура способа совершения преступления по уголовным де лам о фальсификации доказательств и (или) результатов оперативно-розыскной деятельности. М. 2016. С. 101-103.

\section{References}

1. Appeal determination of the Ju dicial Collegium of the La ngepass City Court of the Khanty-Mansiysk Autonomous Okrug of April 12,2018 in case N 22-411. Archive of the Langepass City Court of the Khanty-Mansi Autonomous Okrug (in Russian).

2. Averyanova, T.V., Rossinskaya, E.V. (1999). Encyclopedia of forensic exa mination [Entsiklopediya sudebnoy ekspertizy]. Moscow (in Russian).

3. Baranov, A.M. (2006). Ensuring legality in pre-trial criminal proceedings [Obespecheniye zakonnosti v dosudebnom proizvodstve po ugol ovnym delam]. Omsk: Omsk Academy of the Ministry of Internal Affairs of the Russian Federation (in Russian).

4. Bel kin, R.S. (1999). Forensic s cience: educational reference dictionary [Kri minalistika: uchebnyy slovar'-spravochnik]. Moscow (in Russian).

5. Meshcheryakov, V.A. (2004). El ectronic digital objects in criminal process and cri minalistics [Elektronnyye tsifrovyye ob "ye kty v ugolovnom prots esse i kriminalistike]. Voronezh fore nsic readings: combined scientific works, 4, 153-169 (in Russian).

6. Polya kov, V.V. (2006). On the issue of enhancing the effectiveness of investigating crimes in the field of computer information [K voprosu o povyshenii effektivnosti rassledova niya prestupleniy $v$ sfere komp'yuternoy informatsii]. Actual problems of combating crimes and other offenses. Proceed. Fourth Int. Scientific a nd Practical Conference. Barnaul (in Russian).

7. Polya kov, V.V., Shebalin, A.V. (2013). To the issue of using the concepts of "virtual tra ces" a nd "electronic digital traces" in foren sic science [K voprosu ob ispol'zovanii ponyatiy "virtual'nyye sledy" i "elektronno-tsifrovyye sledy" v kriminalistike]. Actual problems of combating crimes a nd other offenses. Proceed. XI Int. Scientific and Pra ctical Conference. Barnaul: Barnaul Law Institute of the Mi nistry of I nternal Affairs of Russia. Part 1 (in Russian).

8. Polyakov, V.V. (2012). On high-tech methods of committing crimes in the field of computer information [O vys okotekhnologichnykh sposobakh soversheniya prestupleniy v sfere komp'yuternoy informatsii]. Criminal procedural and forensic readings in Altai: $m$ a terials of the a nnual All-Russian s cientific-practical conference dedicated to the 50th a nnive rsary of the Faculty of La w a nd the 40th a nniversary of Al tai State University. Barnaul. Altai State University Press, 11-12, 123-126 (in Russian).

9. Polya kov, V.V. (2008). On the use of new concepts in proving crimes in the field of computer information [Ob ispol'zova nii novykh ponyatiy pridokazyva niiprestupleniy vsfere komp'yuternoyinformatsii]_Russian legalscience: state, problems, prospects. Proceed_All-Russianscientific- 
practical conference dedicated to the 45th an niversary of legal education in Altai, September 19-20, 2008. Ba rnaul (in Russian).

10. Polyakov, V.V. (2010). Features of training specialists for the investigation of crimes related to una uthorized remote access to computer information [Osobennosti podgotovki spetsialistov dlya rassledovaniya prestupleniy, svyazannykh s nepravomernym udalennym dostupom k komp'yuternoy informatsii]. Izvestiya of Al tai State University, 2(1), 96-97 (in Russian).

11. Polyakov, V.V. (2008). Results of questioning in cases of unauthorized remote access to computer information [Rezul'taty a nketirovaniya po delam o nepravomernom udalennom dostupe k komp'yuternoy informatsii]. Cri minal procedural and forensic read ings in Altai. Proceed. Interregional scientific-practical conference. Barnaul: Publishing house of the Al tai State University, 7, 245-249 (in Russian).

12. Safronov, A.Yu. (2015). On the need to distinguish between falsification and conscientious delusion in the course of conducti ng inspections on claims (reports) about falsifying evidence and falsifying the results of operational-search activity [O neobkhodimosti razgranicheniya fal'sifikatsii i dobrosovestnogo zabluzhdeniya $v$ khode proizvodstva proverok po zayavleniyam (soobshcheniyam) o fal'sifikatsii doka zatel'stvi fal'sifikatsii rezul'tatov operativno-rozysknoy de yatel'nosti]. Tomsk (in Russian).

13. Sa fronov, A.Yu. (2017). Methods of committing a crime in criminal cases of falsification of evi dence and (or) the results of operationa I investigative activities [Sposoby soversheniya prestupleniya po ugolovnym delam o fal'sifikatsii dokazatel'stv i (ili) rezul'tatov operativnorozys knoy deyatel'nosti]. Barnaul (in Russian).

14. Safronov, A.Yu. (2016). Structure of the method of committing a crime in criminal cases of falsification of evidence and (or) the results of operational investigative a ctivities [Struktura sposoba soversheniya prestupleniya po ugolovnym delam o fal'sifikatsii dokazatel'stv i (ili) rezul'tatov operativno-rozysknoy deyatel'nosti]. Moscow (in Russian).

15. The sentence of the Moscow City Court in case No. 2-0020 / 2018 of July 2, 2018). Appeal definition of the Judicial Collegium for Criminal Cases of the Supreme Court of the Russian Federation of Nove mber 7, 2018 N 5-APU18-67 / Archive of the Moscow City Court of Moscow, 2018 (in Russian).

16. Vasyukov, V.F. (2016). Seizure of electronic media: unsolved problems of practice [Iz"yatiye elektronnykh nositeley informatsii: nereshennye problemy praktiki]. Criminal trial, 2, 54-57 (in Russian) (in Russian).

17. Vekhov, V.B. (2005). Main directions of development of forensic investigation of computer information and its material camiers [Osnovnyye napravleniya ra zvitiya kriminalisticheskogo issledova niya komp'yuternoy informatsii i yeye material'nykh nositeley] / V. B. Vekhov/ Dis closure and investigation of crimes involving the use of computer technology: problems, trends, prospects. Proce ed. All-Russian Scientific and Practical Conference. Moscow (in Russian).

18. Vekhov, V.B. (2008). Bases of the criminalistic theory of research and the use of computer information and the means of its processing [Osnovy kriminalisticheskogo u cheniya ob issledovanii i ispol'zovanii komp'yuternoy informatsiii sredstv yeye obrabotki]. Vo lgograd (in Russian).

19. Zaitsev, P. (2002). El ectronic document as a s ource of evidence [Elektronnyy dokument kak istochnik dokazatel'stv]. Legality, 4, 4044 (in Russian).

\section{Citation:}

Сафронов А.Ю., Поляков В.В. Проблемы юридического и лингвистического определения фальсификации доказательств в уголовном судопроизводстве // Юрислингвистика. -2019. - №12. -С. 14-19.

Safronov, A.Yu., Polyakov, V.V. (2019). Problems of legal and linguistic definition of evidence tampering in criminal court procedure. Legal Linguistics, 12, 14-19.

(cc) $\mathrm{Er}$ 